\title{
A sampler making discrete spore prints, useful for spore release studies
}

\author{
TIMO KURKELA
}

\begin{abstract}
KURKELA, T. 1994: A sampler making discrete spore prints, useful for spore release studies. - Karstenia 34:61-64. Helsinki. ISSN 0453-3402

A spore trap in which suction time, air flow, and time intervals may be varied is described. During each sampling interval, air spora are collected at the periphery of a standing drum, making discrete spore prints on an adhesive surface. At the end of the total sampling period, the tape is cut into small pieces and mounted for example in Kaiser's glycerine for microscopy. This sampling device has proved especially useful in spore release studies.
\end{abstract}

Key words: spore release, spore trap

Timo Kurkela, Finnish Forest Research Institute, FIN-01301 Vantaa, Finland

\section{Introduction}

Several types of spore samplers have been described for the study of spore production and dissemination. The most advanced samplers are those which take volumetric, continuous, and/or discrete samples over a given period (Panzer et al. 1957, Hirst 1952, Davis and Sechler 1966, Wood and Schmidt 1966, Kramer and Pady 1966). The most widely used spore trap is still perhaps the Burkard Volumetric Spore Trap. It is a modified Hirst Spore Trap (Kurkela 1973, Mitchell et al. 1978, Hayes 1980, Laflamme and Archambault 1990). Typically, spores are collected on microscopic slides or on some type of plastic tape coated with vaseline or other adhesive. Adhesive is not needed if the spores under investigation have a gelatinous, sticky surface.

Despite the existence of so many different devices, a simple inexpensive spore trap, incorporating the best features of the more sofisticated traps has been lacking. In the following, I describe a spore trap with an easily adjustable timer and simplifications in the handling of spore samples.

\section{Description}

The sampler consists of three main components: A) an airtight acrylic box, which is connected to B) an electric timer which makes a full turn every 60 minutes, and C) a vacuum pump.

A) The sampler unit (the acrylic box) is assembled from the following parts (Fig. 1):

$1=$ Electric wire connecting the box to the timer.

$2=$ Plastic tube connected to the air pump.

$3=$ Tube to an airtight vessel to drain off condensation.

$4=$ A conical orifice $(0.5 \times 14 \mathrm{~mm})$ through which air flow is forced against the drum surface.

$5=$ Removable acrylic plate to which the next three components are attached:

$6=$ A synchronic drive motor for A.C. current $(250 \mathrm{rpm}$, $50 \mathrm{~Hz}$ )

$7=\mathrm{A}$ gear box to transform $250 \mathrm{rpm}$ to one revolution every six hours.

$8=$ An acrylic drum with a diameter of $183(+2) \mathrm{mm}$.

$9=$ Power source connection box.

The outer periphery of the drum (8) forms a collection surface $22 \mathrm{~mm}$ wide, with a $1 \mathrm{~mm}$ wide and $1 \mathrm{~mm}$ high rim on the both edges. Thus the outer periphery provides a $20 \mathrm{~mm}$ wide, flat surface suitable for $19 \mathrm{~mm}$ wide tape. The drum, which is fastened directly on to the axle of the gear box, with a screw, is easily removed. 


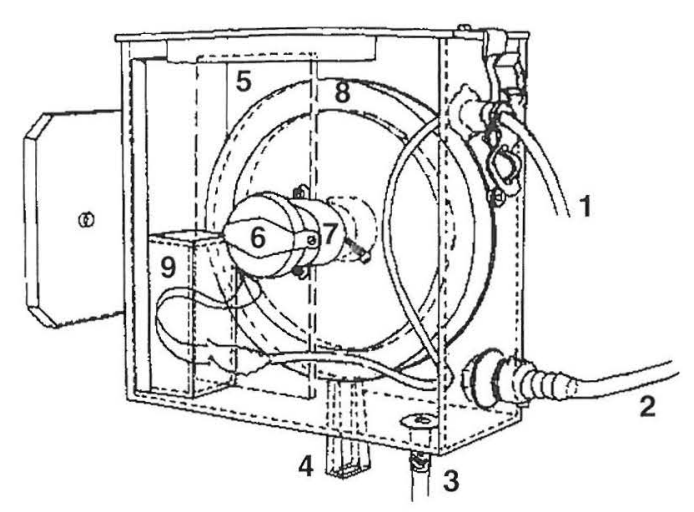

Fig. 1. Spore trap used to obtain discrete spore prints at adjustable time periods from 2.5 minutes to several hours. For numbers $1-9$, see previous page.

Constant air flow is maintained with a suction pump, where the adjustable air flow is monitored between the trap and pump. The timer is a standard device, consisting of a drum making one round per hour. It has two circuits, one for the sampler unit and the other for the pump. The shortest time setting on the drum $2.5 \mathrm{~min}$, corresponding to a $4 \mathrm{~mm}$ movement of the trapping surface: therefore the free distance between discrete spore prints is about $3.5 \mathrm{~mm}$. While the trapping drum is in motion the pump circuit is disconnected. The maximum number of spore prints for one hour is 12 . In one hour it is also possible to use several suction times for one spore print, e.g., one print per hour with two 5 min suction periods and two 25 min quiet periods with the pump disconnected.

Spores are trapped directly onto the drum surface, on which a very thin coat of purified vaseline is used as an adhesive. An adequate coating is easily obtained if after treatment of the whole drum surface the excess vaseline is almost wiped off with a clean tissue paper. Spores attached to the drum are transferred onto transparent tape (19 mm wide Scotch ${ }^{\mathrm{TM}}$ Magic $^{\mathrm{TM}}$ ) by pressing the adhesive side against the trapping surface. While still attached to the drum, the site of each spore print is marked with a pencil on the edge of the tape. (Notes can also be made on the tape for future identification.) The tape is then removed, cut into pieces, and mounted, for example, in gelatine glycerine (Kaiser's) on a standard objective slide with the adhesive side of the tape up. An easily handled number of spore prints per slide is 12 , when $50 \times 24 \mathrm{~mm}$ cover glasses are used. Spores adhering to the adhesive of the tape remain in place very well during handling. Because of the conical shape of the orifice, the narrowest prints (about $0.25 \mathrm{~mm}$ ) are obtained with relatively large living spores and the prints become broader if most of the obtained material consists of dry, small size dust particles (Fig. 2).

The adhesive on the tape has some patterning, allowing coloured spores to be detected by standard light microscopy and small hyaline spores by using phase contrast with a magnification of $10 x$ 20 or greater. Because the number of spores in the prints may significantly differ according to the position on the tape, each print must be systematically examined by the same method. Spores should be counted in a certain number of fields of view along the centre line of the print. The number of fields can be chosen according to situation. Typically the fields in a print are very widely variating when air is water-saturated in foggy or rainy weather at relatively low temperature. In such conditions condensed water at the inner edge of the orifice may collect spores, wich are then occasionally released together with small water droplets and attached on the drum surface.

\section{Discussion}

The design of this sampler allows the following items to be adjusted: 1) number of spore prints per hour or per day depending on the type of timer, 2) the length of suction period for one print, 3) the number of suction periods for one print, and 4) air flow through the equipment (orifice). The maximum number of spore prints per drum is 143 , which means that it is possible to operate the trap continuously for almost six days (assuming one print per hour).

Fig. 2A-D. Two examples of spore prints. - A-B) ascospores of Neofabraea populi obtained in moist weather after rain and, C-D) material trapped during dry weather consisting mainly of Cladosporium conidia and dust particles. B and D are partial magnifications from $\mathrm{A}$ and $\mathrm{C}$, respectively. Scale bar indicates $0.25 \mathrm{~mm}$ in $\mathrm{A}$ and $\mathrm{C}$, and $20 \mu \mathrm{m}$ in B and D. 
A $\quad \xi \cdots$

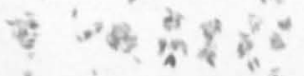
At

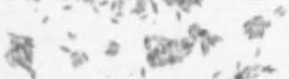
a $x^{2}=0$

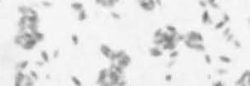
$6: 20 \%$ or

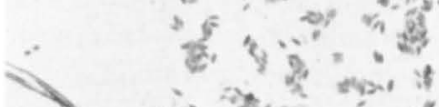

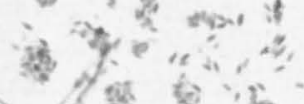

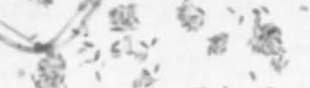

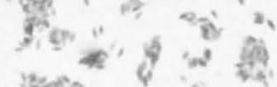

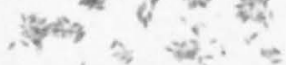
Gu' 19, 我, in 㺼: $3,3,3$

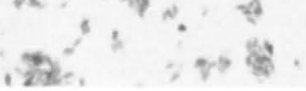
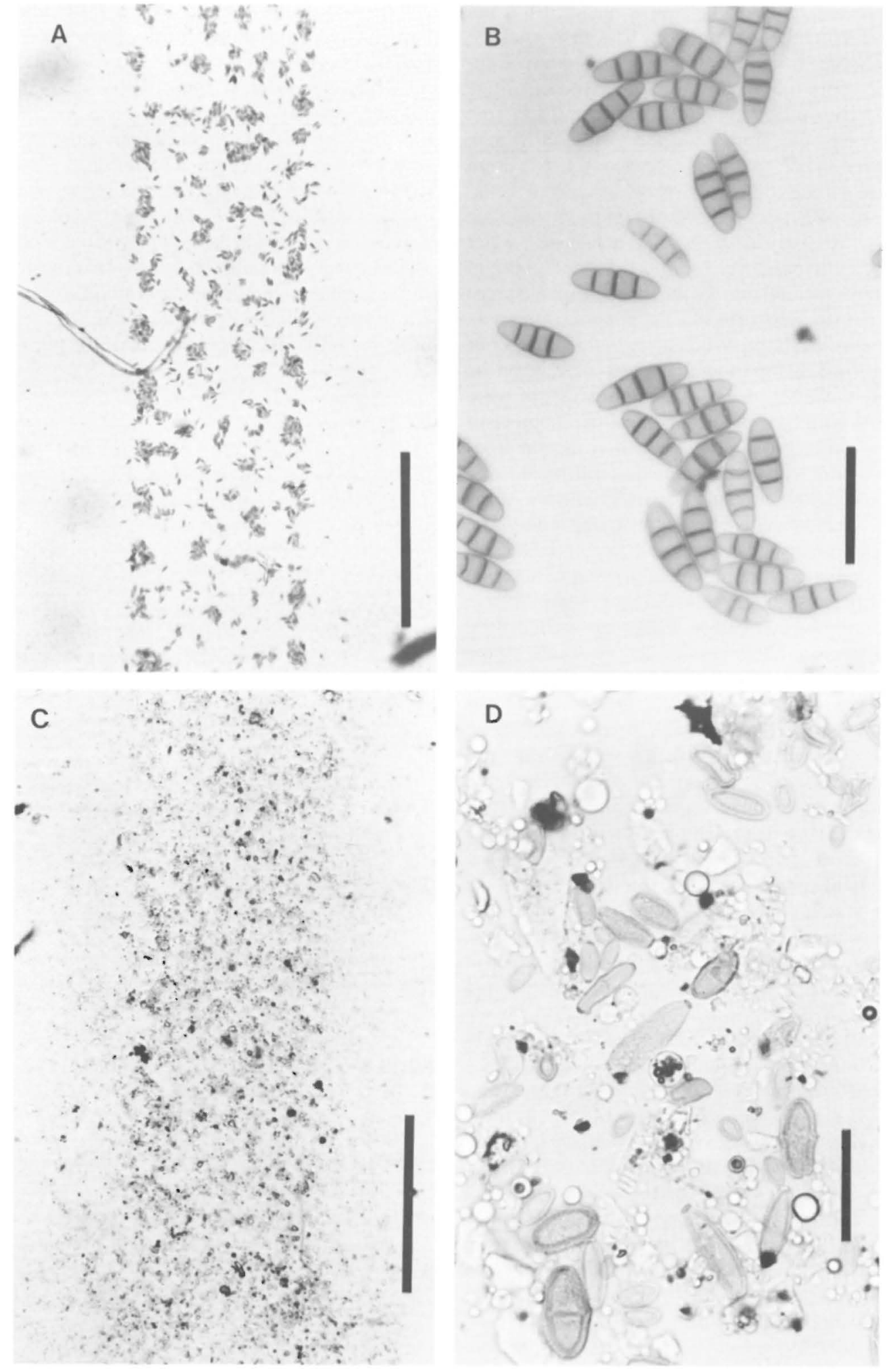
The reliability of the results obtained has not been separately investigated. The efficiency to catch spores is comparable with that of any volumetric spore trap having the same type of orifice construction in relation to the trapping surface of the drum, e.g. the Burkard Spore Trap in which, however, the drum rotates continuously. The drum surface is coated with vaseline instead of being covered with tape because the glue on the tape surface is easily destroyed by condensed water during moist weather. The most difficult phase in the above method may be the transferring of spores from the vaseline surface of the trapping drum onto the transparent tape. When a very large number of spores (one on top of another) was attached to the drum, however, a second application of tape yielded no more spores. An excessive number of spores can be avoided by using short suction times for one print, or by weakening the air flow. Weaker air flow, however, causes lower efficiency in the spore catch. With the sampler operating at $10 \mathrm{l} / \mathrm{min}$, particles with a diameter of $4 \mu \mathrm{m}$ or larger are impinged on the drum, when the distance between the orifice and the drum is $0.5 \mathrm{~mm}$ (May 1967).

During foggy weather, water may be condensed and appears as a thin coat around the spores on the vaseline surface. The air flow from the orifice may then blow water droplets containing spores off the desired spore print. This problem can be minimized by using a low air flow, no stronger than is needed to catch the spores of interest of a particular study. The same problem of water droplets is met with Burkard Spore Trap, although the erroneous distribution of spores is not recognizable since the continuous rotation of the drum. Allowing the trapping drum to dry for perhaps half an hour, after it has been removed from the trap would reduce the amount of water on the drum to a level where it would not interfere in transferring the spores onto the tape.

Thus far the sampler has been used to study spore release in several fungi, including $\mathrm{Cla}$ dosporium spp., Neofabraea populi Thompson (Fig. 2), Phacidium infestans Karst., Lophodermella conjuncta (Darker) Darker, and Ochroporus tremulae (Bond.) Fiasson \& Niemelä. Some preliminary results have already been published concerning the release of ascospores by $P$. infestans (Kurkela 1993). This type of study can be conducted with stationary equipment by placing the orifice close to the spore source. For volumetric investigation of air spora, the sampler should be furnished with a vane to keep the orifice against the wind; this requires a more complicated construction, like that described by Czabator and Scott (1970).

Because of its simple construction, the sampler has run reliably in continuous use for several months. The only disturbance was caused by insects blocking the orifice. The trap can easily be modified by changing the electromechanical timer to a time release device to control the running of the synchronic motor and the air pump. Such a change would make it possible to adjust the time for air suction and drum movement to periods shorter than 2.5 minutes. For long suction times, the original timer is useful and reliably operates the pump.

\section{References}

Czabator, F.J. \& Scott, O.J. 1970: New sampler makes discrete spore prints for specified time intervals. Plant Disease Reporter 54: 498-500.

Davis, D.R. \& Sechler, D. 1966: A simple, inexpensive, continuous sampling spore trap. - Plant Disease Reporter 50: 906-907.

Hayes, A.J. 1980: Spore liberation in Crumenulopsis sororia. - Trans. Br. Mycol. Soc. 74: 27-40.

Hirst, J. M. 1952: An automatic volumetric spore trap. Ann. Appl. Biol. 39: 257-265.

Kramer, C. L. \& Pady, S.M. 1966: A new 24-hour spore sampler. - Phytopathology 56: 517-520.

Kurkela, T. 1973: Epiphytology of Melampsora rusts of Scots pine (Pinus sylvestris L.) and aspen (Populus tremula L.). - Commun. Inst. For. Fenniae 79(4): 1-68.

Kurkela, T. 1993: Production and release of ascospores by Phacidium infestans, a snow blight fungus on Scots pine. - Finn. For. Res. Inst., Research Papers 451: 139-144.

Laflamme, G. \& Archambault, L. 1990: Evaluation of microclimatic factors affecting ascospore release of Gremmeniella abietina var. balsamea. - Can. J. Plant Pathol. 12: 190-194.

May, K. R. 1967: Physical aspects of sampling airborne microbes. In: Gregory, P. H. \& Monteith, J. L. (eds.), Airborne microbes: 60-80. — Symp. Soc. Gen. Microbiol., Univ. Press Cambridge.

Mitchell, C. P., Millar, C. S. \& Williamson, B. 1978: The biology of Lophodermella conjuncta Darker on Corsican pine needles. — Eur. J. For. Pathol. 8: 108118.

Panzer, J.D., Tullis, E.C. \& Van Arsdel, E.P. 1957: A simple 24-hour slide spore collector. Phytopathology 47: 512-514.

Wood, F.A. \& Schmidt, R.A. 1966: A spore trap for studying spore release from basidiocarps. Phytopathology 56: 50-52.

Received on 21 June 1994 